\title{
VALOR E PRESTÍGIO COM A PROFISSÃO EM ADMINISTRAÇÃO
}

\section{VALUE AND PRESTIGE TO THE PROFESSION IN BUSINESS MANAGEMENT}

Ricardo Braga Veroneze

Doutorando do Programa de Pós-Graduação em Administração da Universidade Federal de Lavras - UFLA

Lavras, MG, Brasil

E-mail: rbveroneze@gmail.com

Dalton de Sousa

Professor Adjunto da Universidade Federal de Mato Grosso do Sul - UFMS

Paranaíba, MS, Brasil

E-mail: dalton.sousa@gmail.com

Daniel Carvalho de Rezende

Professor e Coordenador do PPGA da Universidade Federal de Lavras - UFLA

Lavras, MG, Brasil

E-mail: danielderezende@dae.ufla.br

André Siqueira Rennó

Professor do Centro Universitário de Formiga - FUOM

Divinópolis, MG, Brasil

E-mail: andrerenno89@gmail.com

\section{RESUMO}

A formação acadêmica em administração propicia inúmeras possibilidades profissionais, contemplando diferentes segmentos de trabalho, tais como, pesquisa, consultoria, empreendedorismo, além de outros caminhos. Essa dinamicidade contribui para um grande leque de opções que impõem diferentes desafios ao futuro profissional da administração. Nesta direção, este trabalho, que pertencente a área de ensino e pesquisa em Administração, procura compreender $\mathrm{o}$ valor percebido, o prestígio e a identificação com a profissão sob a perspectiva dos estudantes de graduação de duas universidades federais. Muito presente em outras áreas, ainda há carências desse tipo de estudo nas ciências administrativas. A amostra foi obtida aplicando questionários junto aos estudantes de Administração. Os resultados mostram que muitos graduandos em administração estão ainda indecisos com a profissão, mas, há também aqueles cuja identificação com a mesma é clara, sendo que a maioria visa um trabalho futuro, seja na iniciativa privada ou no serviço público. A partir da análise dos dados foi possível à formação de dois clusters, o primeiro grupo foi denominado de vocacionado, o qual, pode dizer que estão mais satisfeitos $e$ identificado com 0 curso de Administração e outro chamado de indecisos, o qual possui um grau menor de identificação e satisfação com o mesmo. Por fim, foi verificado que o grupo dos vocacionados possuem ambições maiores, tal como abrir sua própria empresa, do que apenas se preparar para conseguir um emprego (público ou privado).

Palavras-chave: Valor. Identidade. Prestígio. Formação Acadêmica. Administração.

\section{ABSTRACT}

The academic formation in administration offers innumerable professional possibilities, contemplating different segments of work, such as, research, consultancy, entrepreneurship, besides other ways. This dynamism contributes to a wide range of options that pose different challenges to the future professional of the administration. In this direction, this work, which belongs to the area of teaching and research in Administration, seeks to understand the perceived value, prestige and identification with the profession from the perspective of undergraduate students from two federal universities. Very present in other areas, there is still a lack of this type of study in the administrative sciences. The sample was obtained by applying questionnaires to the students of Administration. The results show that many undergraduates in management are still undecided by the profession, but there are also those whose identification with the same is clear, most of which is aimed at future work, either in the private sector or in the public service. From the analysis of the data it was possible to form two clusters, the first group was called vocation, which can say that they are more satisfied and identified with the course of Administration and another called undecided, which has a lower degree Identification and satisfaction with it. Finally, it was verified that the group of vocationates have bigger ambitions, such as starting their own company, than just preparing to get a job (public or private).

Keywords: Value. Identity. Prestige. Education. Administration.

Data de aprovação: 04 de junho de 2017.

Data de submissão: 12 de outubro de 2016. 


\section{INTRODUÇÃO}

A formação profissional é um processo mais complexo do que aparentemente demonstra (OLIVEIRA, 2011). O dinamismo do mundo atual tem transformado o mercado de trabalho para praticamente todas as profissões de nível superior. Isso impõe ao estudante de graduação uma atenção redobrada à sua formação, que deve ir além do curso superior, e o faz pensar em uma formação continuada ao longo de toda a sua carreira, mas que tem início com a decisão do curso e da instituição de ensino superior (SILVA; CUNHA 2002).

Em especial, o curso de bacharelado em administração encontra-se entre os cursos com maior número de alunos matriculados no ensino superior. Conforme aponta o Censo da Educação Superior elaborado pelo INEP no ano de 2015, encontravam-se matriculados 793.564 alunos nos cursos que formam futuros Administradores, os quais representam 12\% do universo de alunos matriculados em Instituições de Educação Superior (IES) brasileiras. A formação superior em administração propicia inúmeras possibilidades profissionais, seja como professor/pesquisador, empreendedor, consultor, trabalhador da iniciativa privada, servidor público, dentre outras. Todavia, conforme mostrado, a concorrência no mercado de trabalho é grande e, muitas vezes, envolverá muitas outras profissões, impondo ainda mais desafios ao futuro profissional da administração (CFA, 2015).

Por sua vez, a escolha de uma instituição de ensino superior de prestígio e renome pode ser uma forma de diferencial na carreira, uma vez que se acredita que estas são capazes de oferecer mais qualidade de formação se comparada a instituições de menor credibilidade. Alguns aspectos importantes emergem na questão da escolha da universidade e, principalmente, do curso. $O$ valor que o estudante percebe (REICHHELD, 1996), o prestígio que ele sente (LINO, 2004) e identificação que ele adquire com a profissão (SANTOS, 1990) são fatores essenciais que conduzem a plena satisfação com a carreira escolhida.

No Brasil, em geral, as instituições públicas de ensino superior (federais e estaduais) são, muitas vezes, reconhecidas como provedoras de ensino superior com nível de qualidade superior à maioria das instituições privadas.

Dessa forma, este trabalho procura compreender, sob a perspectiva dos estudantes de graduação de universidades federais, o valor percebido, prestígio e a identificação com a profissão, semelhantemente aos trabalhos de Costa e Oliveira (2011) e Costa e Oliveira (2008), bem como, as possíveis relações entre tais construtos.

Para tal, apresenta-se o seguinte problema central de pesquisa: como os estudantes de Administração de duas universidades federais avaliam seus cursos, considerando as perspectivas do serviço de formação recebido, da profissão, e da identificação pessoal?

Diante desse problema de pesquisa, foram propostos os seguintes objetivos: (1) analisar a percepção de valor dos estudantes no serviço de formação recebido, o nível de identificação do aluno com a profissão e a percepção de prestígio na profissão; (2) desenvolver uma tipologia dos estudantes a partir dos tópicos temáticos da pesquisa (valor, identificação e prestígio); (3) identificar relações entre os construtos.

Foi levantada uma amostra com cento e sete estudantes de administração de duas universidades federais. Os dados são analisados quantitativamente por meio de diversas técnicas estatísticas, como a análise fatorial, análise de clusters, análise discriminante e a análise de regressão múltipla por mínimos quadrados ordinários. 
Acredita-se que os estudos sobre o ensino e a pesquisa em negócios têm relevante papel no desenvolvimento do conhecimento da área, pois permitem mais entendimento acerca do processo de formação e também por indicarem meios para adequar a área às demandas, continuamente em transformação, da sociedade (COSTA; OLIVEIRA, 2009).

Os resultados levaram à formação dos seguintes fatores: valor epistêmico, valor de reputação/imagem, valor social, valor funcional (desejo de satisfação), identificação com a profissão e prestígio. Os estudantes foram classificados em dois grupos: (1) vocacionados - identificados com a profissão; e, (2) indecisos profissionalmente. Quanto ao relacionamento entre os construtos, verificou-se que o Valor Funcional é explicado em parte pelo Valor Epistêmico, pelo Valor Social e pela Identificação com a Profissão.

Espera-se que este trabalho possa contribuir para o aprimoramento das estratégias e das práticas de gestão dos cursos superiores em administração, por possibilitar uma visão geral acerca de como os estudantes avaliam seus cursos, suas instituições, bem como suas identificações com a profissão. Esta pesquisa poderá auxiliar gestores de instituições de ensino, além de coordenadores de cursos, na avaliação da satisfação dos estudantes de administração, viabilizando, assim, um planejamento a longo prazo, mediante as suas necessidades. Ademais, com o amparo dos resultados, poderá ser formulada estratégias que visem frear a evasão no curso de Administração, que ainda continua com índices elevados no Brasil.

Cientificamente, este trabalho contribui para a área de ensino e pesquisa em Administração, por oferecer uma caracterização de perfil, baseado na análise de cluster, de dois grupos de estudantes vinculados a universidades federais. Outros estudos podem tomar como referência estes resultados, replicando-os em outras instituições, independentemente se forem de natureza pública ou privada.

\section{REFERENCIAL TEÓRICO}

Nesta seção são apresentadas as principais fundamentações teóricas que nortearão o desenvolvimento deste trabalho, desta maneira inicialmente é apresentado o estado da arte sobre a temática abordada nessa pesquisa que está relacionada a: valor percebido no curso, percepção do prestígio e identificação com a profissão.

Um trabalho relevante sobre esse tema foi desenvolvido por Gonçalves (2015), ele afirma que o jovem, futuro gestor, vivencia grandes dificuldade em caracterizar-se como ser humano e diferenciar seus valores pessoais de seus conhecimentos profissionais. O estudo lançou luz para a necessidade de planejar, alinhar e direcionar a formação do jovem estudante administração quanto a sua formação humanística e profissional, estabelecendo aprendizado sobre a autoestima e autoconfiança aliada por aquisições de conhecimento de gestão comercial/empresarial.

Outra pesquisa importante em relação a formação acadêmica do estudante de administração foi realizada por lizuka (2014), porém, nesse caso, voltada para a importância do empreendedorismo nessa formação. Segundo esse autor a instituição de ensino não pode adotar uma única estratégia de ensino, pesquisa e extensão, pois os interesses e necessidades dos discentes captadas em sua pesquisa demonstraram que os alunos com baixo potencial e perfil empreendedor não estão abertos a aprenderem assuntos relacionados ao empreendedorismo. Assim, é muito provável que, ainda que houvesse as melhores 
alternativas para estimular e concretizar o empreendedorismo, esses alunos continuariam a avaliar negativamente o ambiente universitário. O desafio para as instituições de ensino é propiciar um ambiente universitário plural e flexível, tanto quanto possível.

Costa (2008) realizou um estudo com uma proposta parecida a deste estudo, porém em universidades do Ceará. Nesse trabalho esse autor verificou que os resultados indicaram que as avaliações dos alunos são mais positivas nos dois primeiros anos de curso, período em que os alunos demostram um elevado entusiasmo. Por outro lado, o entusiasmo cede lugar a um posicionamento crítico, na medida em que os estudantes avançam no curso. Para esse autor, é normal que com a maturidade adquirida ao longo do curso, ou mesmo por uma melhor capacidade de avaliação da profissão e da própria vocação, os estudantes se mostrem mais críticos, na medida em que avançam no curso

Após esse recorte teórico sobre os estudos recentes relativos a essa temática de pesquisa nas próximas sessões abordaremos os tópicos que explicam melhor a teoria que embasam esse trabalho.

\section{Valor percebido no curso}

De acordo com Costa e Oliveira (2008), a literatura sobre Valor percebido está extensamente desenvolvida na área de Marketing. Entretanto, Zeithaml (1988) ressalta a dificuldade em conceituar e definir, de fato, o que é valor para os clientes. Para a autora, qualidade e valor não são sinônimos "valor é mais individual e pessoal que a qualidade... e envolve a diferença entre o que se dá e o que se recebe, enquanto que a qualidade está relacionada apenas ao recebimento na equação de valor" (ZEITHAML, 1988, p. 14).

Em sua pesquisa, Zeithaml (1988) identifica diversas definições do consumidor para valor e as classifica nos seguintes grupos: valor é preço baixo; valor é aquilo que se busca num produto, os atributos qualitativos e quantitativos importantes; valor é a qualidade percebida pelo que é pago; e valor é aquilo que se recebe em troca do que se dá.

Corroborando, Sirdeshmukh, Singh e Sabol (2002) definem valor como a percepção dos consumidores em relação à diferença entre os benefícios e os custos de manter um relacionamento com um provedor de serviços, devendo as trocas relacionais proporcionarem o maior valor possível aos clientes. Gutman (1982) acrescenta que valor, cuja percepção é situacional, relaciona-se a sentimentos como desejo, felicidade, segurança e prazer e que através da influência e percepção de tais fatores, o consumidor fará suas escolhas sobre produtos e serviços.

Para Houston e Gassenheimer (1987) a existência de valor está condicionada a existência de benefícios mútuos, entre consumidor e empresa, no processo de troca, ou seja, o conceito de valor não deve ser relacionado a uma situação de perda e ganho. De acordo com esses autores, o valor é percebido pelo consumidor através de duas diferentes avaliações: do produto ou serviço que está adquirindo e das ações e experiências vividas durante o processo de troca.

Segundo Gardner (2001, p. 41) "valor é a percepção em relação ao mercado, no qual o consumidor compara sua empresa com seus competidores" e através dessa comparação e da manutenção de uma posição favorável no mercado é que a empresa oferecerá valor para o cliente.

Num estudo com usuários de internet banking num grande banco de varejo no Brasil, Brei e Rossi (2002) verificaram um forte e significante impacto da confiança do consumidor sobre o valor percebido, 
demonstrando a relevância da construção da confiança no relacionamento entre empresa e cliente. Para os autores, tal importância é concretizada quando os clientes percebem que o valor de manter o relacionamento é bastante positivo. Brei e Rossi (2002) concluíram que a obtenção da lealdade requer tanto o desenvolvimento da confiança, quanto a percepção pelos clientes de que há entrega de valor nas relações de troca com a empresa.

Afirmam Gassenheimer, Houston e Davis (1998) que, quanto maior o investimento em relacionamentos ou quanto menor a distância relacional, a transação terá menor valor econômico e maior valor social. Por outro lado, quanto maior for a distância relacional, a percepção de valor estará altamente relacionada ao valor econômico e pouco identificada com o valor social.

Parafraseando Reichheld (1996), a criação de valor para o aluno gera lealdade e esta, por sua vez, gera crescimento, mais alunos e recursos (projetos, investimentos etc.) e mais valor para todos no ambiente acadêmico.

Para Sheth, Newman e Gross apud Costa e Oliveira (2011) e Costa e Oliveira (2008), o valor é caracterizado em uma perspectiva multidimensional, com cinco categorias:

1. Valor Funcional: se refere aos atributos do bem ou serviço que está sendo adquirido, está mais associado às especificações técnicas do produto e a sua utilidade primária e também a relação entre qualidade e preço;

2. Valor Social: motivação social para o consumo;

3. Valor Emocional: um produto consumido também pode afetar os sentimentos dos compradores e consumidores, tanto de forma positiva como negativa;

4. Valor Epistêmico: há diversos tipos de produtos comprados ou adquiridos que são fortemente motivados pela possibilidade que têm de gerar conhecimentos ou satisfazer a alguma curiosidade;

5. Valor Condicional: há circunstâncias em que uma determinada escolha de consumo está condicionada por algo em especial, sem as quais tal decisão seria relativizada. O consumo é resultado de uma situação específica.

A seguir, são apresentados os fundamentos a respeito da percepção de prestígio que nortearão o levantamento empírico deste trabalho.

\section{Percepção do prestígio}

Ao buscar literatura a respeito do tema prestígio profissional (ou reputação) encontram-se trabalhos em poucas áreas de estudo, tais como Enfermagem e Pedagogia (LINO, 2004; COSTA; OLIVEIRA, 2008; SOUSA; SILVIA, 2001). Entretanto, quando analisada profundamente a literatura de prestígio profissional relacionada às ciências administrativas, o foco maior de estudo se encontra nas ciências contábeis, apesar de ainda terem poucas pesquisas, comparando-a com as outras áreas já citadas. (MARION, 2001; LACERDA, REIS; SANTOS, 2007; COSTA; OLIVEIRA, 2008; COSTA; OLIVEIRA, 2011.). Embora esse tema pareça ser relevância para os profissionais de Administração, parece ainda não ter despertado o devido interesse dos pesquisadores acadêmicos da área.

Alguns autores buscaram inserir o debate de prestígio profissional, como por exemplo, o trabalho de Costa, Soarez e Brasileiro (2008). Uma explicação possível para tão poucos trabalhos na área pode ser que 
a Administração consiste em uma profissão recente e ainda carente de uma identidade própria. Considera-se que há ainda pouco vínculo entre o conhecimento técnico e acadêmico (COSTA; SOAREZ; BRASILEIRO, 2008).

O prestígio profissional pode ser entendido como sendo a "importância ou significação percebida acerca do trabalho, tanto pelo ponto de vista individual como pelo ponto de vista de outros membros de um grupo social" (LINO, 2004, p. 14). Sendo relevante também realçar a proximidade dos tópicos teóricos 'prestígio' e 'identificação', como observado no trabalho de Santos (1990). Segundo esse autor, existe uma forte aproximação da identificação com a ideia de prestígio, pois, o aspecto principal do conceito de identidade é o reconhecimento que emana das relações sociais e não de uma dimensão mais estritamente pessoal. Para ele, em seu estudo sobre aposentadoria, há uma forte aproximação da identificação com a ideia de prestígio, pois, o aspecto principal do conceito de identidade é o reconhecimento que decorre das relações sociais.

Santos (1990) define o indivíduo a partir de como ele próprio se reconhece no desempenho de papéis sociais e de como é reconhecido pelos outros no meio social. Torna-se possível entender que o prestígio está mais condicionado a um contexto externo. Por sua vez, como será mostrado no próximo tópico, a identificação profissional é mais pessoal.

Desse modo, decidiu-se por avaliar as percepções dos estudantes sobre o prestígio da profissão e sobre si mesmos em relação profissão em Administração. Tais aspectos envolvem elementos de uma atitude e de uma percepção pessoal frente à profissão na qual os estudantes estão se formando. Assim sendo, a análise conceitual será feita em cima de um conjunto de elementos de valor a partir de uma visão ampliada da avaliação que os estudantes da perspectiva futura em termos de satisfação pessoal e status social que a profissão tem, conforme trilharam outros autores (COSTA; OLIVEIRA, 2008, 2011).

\section{Identificação com a profissão}

Para Campos (2000), a identidade profissional refere-se a um conjunto de características que torna uma pessoa semelhante àqueles que exercem uma atividade socialmente reconhecida. Jacques (1997) reforça essa relação indicando que é a importância do trabalho na sociedade (consolidada pelo sistema capitalista, assumindo um papel fundamental na constituição do eu) que dá prestígio, relevância e exaltação ao papel de trabalhador, dando destaque entre os muitos papéis do indivíduo. Tudo isso exprime a relação da identidade com o trabalho.

Segundo identificado por Costa (2008), em alguns textos clássicos, como os de Mintzberg e Drucker, os autores procuraram tangenciar o tema, indicando os riscos e mitos da profissão, mas não foram encontrados estudos orientados especificamente para a análise da identificação pessoal com a profissão.

Para Galindo (2004), além de definir o conceito de identidade, faz se necessário permear o campo no qual se trata a identidade profissional. Segundo a autora, enquanto o debate sobre identidade convida a considerar aspectos ligados ao nível individual, a ideia de profissional leva a pensar em aspectos do social. Dentro desse contexto social a identidade começa a perpassar uma perspectiva de compromisso profissional (BASTOS; CORREA; LIRA, 1998). A partir dessas observações, parte-se da proposição da identificação profissional como a percepção de vinculação pessoal a uma dada profissão, associada à percepção atual ou à perspectiva de satisfação pessoal com o exercício das atividades da referida profissão. 
No contexto deste estudo, a ideia é avaliar a perspectiva atual dos estudantes em relação à satisfação e ao comprometimento futuro com a profissão escolhida. Assim, na próxima seção, será apresentada a metodologia utilizada neste trabalho.

\section{METODOLOGIA}

Realizou-se uma pesquisa descritiva, quantitativa, por meio de um questionário estruturado (survey) aplicado, via internet, a uma amostra de conveniência (em virtude da facilidade de acesso aos respondentes pelos pesquisadores). Os estudos descritivos são aplicados para examinar relações entre variáveis e para fazer previsões específicas. Assim, a pesquisa descritiva é formal e estruturada e a análise dos dados resultantes é realizada valendo-se de métodos quantitativos (HAIR JR. et al, 2005; MALHOTRA, 2001).

A população foi constituída por estudantes de Administração de uma universidade federal em Minas Gerais e de uma outra Federal no Estado do Mato Grosso do Sul. Dessa forma, os dados da amostra foram coletados no mês de novembro de 2014.

Em relação ao instrumento para levantamento dos dados, este trabalho fundamentou-se no trabalho de Costa e Oliveira (2008) e Costa e Oliveira (2011) e, assim, foi replicado o questionário por eles proposto, que foi resumido para adaptar-se ao contexto de instituições públicas. O questionário foi dividido em três blocos: o primeiro apresentou as variáveis de identificação relacionadas à instituição, semestre, tipo de dedicação ao curso (total ou parcial), motivação para realizar o curso e pretensão após a conclusão da graduação. $O$ segundo conteve as questões dos construtos do estudo e o terceiro e último bloco apresentou questões sobre dados demográficos/socioeconômicos.

O Quadro 1 apresenta as variáveis adotadas neste trabalho (COSTA; OLIVEIRA, 2011; COSTA; OLIVEIRA, 2009). O construto Valor foi analisado por meio de vinte e quatro variáveis (Q6.1 a Q6.24), com a exclusão apenas do subconstruto Valor funcional (preço/qualidade), por ter uma formatação direcionada a um público de estudantes do setor privado, sendo utilizadas as seguintes dimensões, cuja ênfase está na profissão: (1) Valor funcional (desejo de satisfação); (2) Valor social; (3) Valor emocional; (4) Valor epistêmico; (5) Valor de reputação (da instituição). Em virtude de se tratar de estudantes de universidades públicas, foram removidas as variáveis do Valor funcional (preço/qualidade). Além dessas, foi adicionada a variável "Entendo que todos os gastos que tenho na realização de meu curso são compensados por tudo o que recebo". Em relação ao Prestígio percebido na profissão, a avaliação foi feita com a utilização de cinco variáveis (Q8.1 a Q8.5), com ênfase dada à profissão. Já a Identificação do estudante com a profissão foi operacionalizada por meio de cinco variáveis (Q7.1 a Q7.5) (COSTA; OLIVEIRA, 2011; COSTA; OLIVEIRA, 2008). Em todas as variáveis para a constituição dos fatores optou-se por utilizar uma escala de concordância/discordância de sete pontos 
Quadro 1 - Perguntas da pesquisa

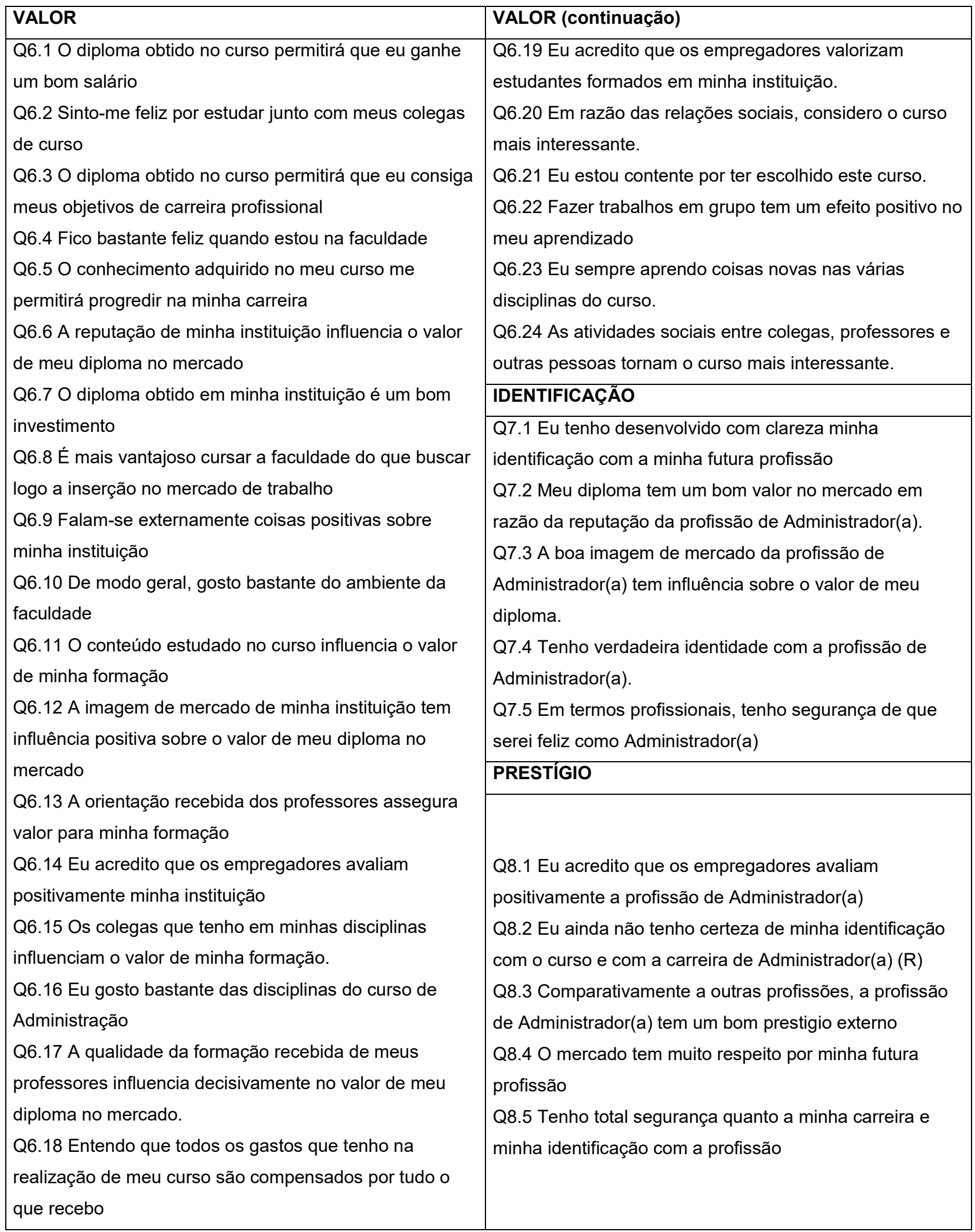

Fonte: Costa; Oliveira (2011) e Costa; Oliveira (2008) 
A análise dos resultados foi realizada por meio de estatísticas descritivas, análise fatorial, análise discriminante, tabulação cruzada. Também foi empregada a análise de regressão múltipla por Mínimos Quadrados Ordinários (MQO), com o objetivo identificar relacionamentos entre os distintos construtos abordados no trabalho.

\section{RESULTADOS E DISCUSSÕES}

\section{Caracterização da amostra}

Com o total dos 107 respondentes da pesquisa, realizou-se uma análise de frequência das variáveis de demografia, demonstradas na Tabela 1.

Em relação à instituição a que fazem parte, 74 alunos (69,20\%) são do curso de Administração da Universidade Mineira (genericamente denominada de IFMinas), sendo o restante de 33 alunos (30,80\%) de Administração da Universidade Sul Matogrossense (genericamente denominada de IFSul). Em relação a distribuição dos respondentes por períodos, analisando de maneira geral, 7,50 \% estão no primeiro período, $1,90 \%$ no segundo, $20,60 \%$ no terceiro, $24,30 \%$ no quarto, $21,50 \%$ no quinto, $4,70 \%$ no sexto, $9,30 \%$ no sétimo, $8,40 \%$ no oitavo, e apenas $1,90 \%$ no nono período. Apesar de uma maior concentração de respostas na faixa mediana dos semestres, isto é, do terceiro até o quinto período, buscou-se ter uma representatividade em todos os períodos possíveis.

Tabela 1 - Caraterização da amostra

\begin{tabular}{llr}
\hline ITENS & & PERCENTUAL \\
\hline \multirow{2}{*}{ Sexo } & Feminino & $50,50 \%$ \\
& Masculino & $49,50 \%$ \\
\hline \multirow{3}{*}{ Faixa Etária } & Até 20 Anos & $38,32 \%$ \\
& De 20 até 22 Anos & $30,84 \%$ \\
& De 23 até 24 Anos & $13,08 \%$ \\
& De 25 até 26 Anos & $4,68 \%$ \\
Estado Civil & Mais de 26 Anos & $13,08 \%$ \\
\hline & Solteiros & $90,65 \%$ \\
& Casados & $8,41 \%$ \\
& Outros & $9,30 \%$ \\
\hline \multirow{3}{*}{ Renda Familiar } & Até $\mathrm{R} \$ 1000,00$ & $10,28 \%$ \\
& Entre $\mathrm{R} \$ 1000,00$ até $\mathrm{R} \$ 2000,00$ & $21,50 \%$ \\
& Entre $\mathrm{R} \$ 2000,00$ até $\mathrm{R} \$ 3000,00$ & $14,02 \%$ \\
& Entre $\mathrm{R} \$ 3000,00$ até $\mathrm{R} \$ 4000,00$ & $15,88 \%$ \\
& Acima de $\mathrm{R} \$ 4000,00$ & $38,32 \%$ \\
\hline
\end{tabular}

Fonte: Dados da pesquisa. 
Quando perguntados a respeito do principal motivo que os influenciaram na decisão de realizar o curso de Administração, a maioria de $57,70 \%$ do total, afirmaram que a preparação para conseguir um emprego (público ou privado) foi o fator mais importante, 19,20\%, apontaram que esperam adquirir conhecimentos para abrir seus próprios negócios, $8,70 \%$ estão se preparando para gerenciar a empresa da família, 3,80\% para poder melhor a prática profissional, 3,80\% por falta de opção, 1,00\% porque o emprego exigia uma formação superior e, por fim, 5,80\% apontaram outros motivos não demonstrado no questionário.

Por sua vez, quando questionados a respeito do estudo, logo após terminarem o curso, de forma geral, $81,00 \%$ dos respondentes pretendem continuar a estudar de alguma forma. Destes, $37,10 \%$ pretendem fazer um curso de especialização, 22,90\% tem a intenção de fazer um curso de mestrado, $11,40 \%$ querem fazer outro curso de graduação, e os restantes 9,50\% marcaram outras opções de estudos. Apenas 19,00\% vão parar de estudar e somente trabalhar, destacando-se a forte consciência da necessidade de formação continuada (SOUSA; OLIVEIRA; REZENDE, 2006).

\section{Análise fatorial}

O Quadro 1 apresenta as variáveis adotadas neste trabalho, sendo que de Q6.1 a Q6.24 foram aquelas utilizadas para verificação de Valor, Q7.1 a Q7.5 para Identificação com o curso e as codificadas de Q8.1 a Q8.5 para verificação de Prestígio, em conformidade com o referencial teórico apresentado.

Para verificar como as variáveis previstas teoricamente para o Valor se agrupavam, foi realizada uma Análise Fatorial. O método de extração utilizado foi o de Componentes Principais, já o método de rotação adotado foi o Varimax. Foram especificados autovalores superiores a 1,4, o que produziu como resultado quatro fatores, conforme a Tabela 2. O Kaiser-Meyer-Olkin (KMO) de adequação da amostra foi de 0,810 e o teste de esfericidade de Bartlett 1020,608, com 276 graus de liberdade e significância de 0,000.

A confiabilidade dos fatores obtidos foi testada por meio do Alpha de Cronbach. Como especificado na Tabela 2, o Fator 1 (valor epistêmico) apresentou um Alfa de Cronbach de 0,849, o Fator 2 (valor de reputação/imagem) 0,789, o Fator 3 (valor social), 0,782 e o Fator 4 (valor funcional) 0,694.

De acordo com Hair et al (2005), o Alpha de Cronbach é uma medidade de confiabilidade cujos valores podem variar de 0 a 1, sendo que a faixa entre 0,600 e 0,700 contém valores considerados dentro do limite inferior de aceitabilidade. Dessa forma, tem-se que as variáveis oferecem boa explicação para cada um dos fatores obtidos.

Em consonância com LeBlanc e Nguyen (1999) e Costa e Oliveira $(2011 ; 2008)$ que definiram que Valor Epistêmico é a capacidade de um produto/serviço em oferecer novidade e/ou satisfazer um desejo de obter conhecimento, o Fator 1 foi dessa forma denominado, conforme a Tabela 2. Por sua vez, LeBlanc e Nguyen (1999) e Costa e Oliveira $(2011 ; 2008)$ afirmam que, para os estudantes, a imagem que sua universidade tem projetada na sociedade está intimamente ligada ao valor do seu diploma. Dessa forma, o Fator 2, pelas características das variáveis que o compõem, foi denominado de Valor de Reputação/Imagem, Tabela 2.

O Valor Social é caracterizado por LeBlanc e Nguyen (1999) e Costa e Oliveira $(2011 ; 2008)$ pela utilidade derivada da associação dos discentes a determinados grupos sociais. Como se pode observar nos resultados deste estudo, este fator está relacionado à sensação de valorização do pertencimento ao grupo. 
Assim, o Fator 3 foi denominado de Valor Social, ou seja, uma motivação social para o consumo de um serviço. Já o quarto e último fator da análise fatorial, Tabela 2, foi denominado de Valor Funcional, que em conformidade com LeBlanc e Nguyen (1999) e Costa e Oliveira (2011; 2008), está relacionada a utilidade econômica, ou seja, aos benefícios associados com a posse do produto/serviço e está subjacente ao desempenho do objeto de uma série de atributos importantes como preço, confiabilidade e durabilidade (na perspectiva deste trabalho, bom salário, alcance de objetivos na carreira profissional e afinidade com o curso).

Tabela 2 - Matriz de componentes rotacionadaa,, confiabilidade, média e desvio padrão

\begin{tabular}{|c|c|c|c|c|c|}
\hline Fator & Questão & Carga & Alfa de Cronbach & Média & Desvio padrão \\
\hline \multirow{8}{*}{ Fator 1 - Valor Epistêmico } & Q6.13 & 0,745 & \multirow{8}{*}{0,849} & \multirow{8}{*}{5,200} & \multirow{8}{*}{0,970} \\
\hline & Q6.16 & 0,730 & & & \\
\hline & Q6.18 & 0,680 & & & \\
\hline & Q6.17 & 0,671 & & & \\
\hline & Q6.11 & 0,660 & & & \\
\hline & Q6.23 & 0,604 & & & \\
\hline & Q6.4 & 0,596 & & & \\
\hline & Q6.5 & 0,582 & & & \\
\hline \multirow{5}{*}{ Fator 2 - Valor de Reputação/imagem } & Q6.6 & 0,731 & \multirow{5}{*}{0,789} & \multirow{5}{*}{5,800} & \multirow{5}{*}{0,800} \\
\hline & Q6.12 & 0,662 & & & \\
\hline & Q6.19 & 0,662 & & & \\
\hline & Q6.14 & 0,650 & & & \\
\hline & Q6.7 & 0,629 & & & \\
\hline \multirow{7}{*}{ Fator 3 - Valor Social } & Q6.9 & 0,737 & \multirow{7}{*}{0,782} & \multirow{7}{*}{5,300} & \multirow{7}{*}{0,970} \\
\hline & Q6.15 & 0,717 & & & \\
\hline & Q6.24 & 0,712 & & & \\
\hline & Q6.2 & 0,625 & & & \\
\hline & Q6.22 & 0,553 & & & \\
\hline & Q6.10 & 0,472 & & & \\
\hline & Q6.20 & & & & \\
\hline \multirow{3}{*}{$\begin{array}{l}\text { Fator } 4 \text { - Valor Funcional (desejo de } \\
\text { satisfação) }\end{array}$} & Q6.1 & 0,633 & \multirow{3}{*}{0,694} & \multirow{3}{*}{4,860} & \multirow{3}{*}{1,140} \\
\hline & Q6.3 & 0,498 & & & \\
\hline & Q6.21 & 0,470 & & & \\
\hline
\end{tabular}

a. Rotação convergida em 6 iterações. Variável Q6.8 removida na análise de confiabilidade.

Fonte: Dados da pesquisa.

Os fatores de Identificação com a Profissão e Prestígio da Profissão, Tabela 3, compostos por cinco variáveis cada, apresentaram os seguintes valores para o Alpha de Cronbach, 0,888 e 0,881, respectivamente, demonstrando que as variáveis oferecem boa explicação para cada um dos fatores.

Tabela 3 - Confiabilidade dos fatores Identificação e Prestígio, média e desvio padrão

\begin{tabular}{lcrrr}
\hline Fatores & \multicolumn{1}{c}{ Variáveis } & Alfa de Cronbach & Média & Desvio Padrão \\
\hline $\begin{array}{l}\text { Identificação com a } \\
\text { Profissão }\end{array}$ & Q7.1; Q7.2; Q7.3; Q7.4; Q7.5 & 0,888 & 4,940 & 1,220 \\
& & & & \\
Prestígio & Q8.1; Q8.2; Q8.3; Q8.4; Q8.5 & 0,881 & 4,390 & 1,230
\end{tabular}

Fonte: Dados da pesquisa. 
Análise de cluster, análise discriminante dos clusters e tabulação cruzada

Com a determinação dos fatores realizada por meio da análise fatorial, realizou-se uma análise de cluster, com o objetivo de verificar os agrupamentos dos acadêmicos por meio de características similares. A análise de cluster visa o agrupamento de indivíduos e não mais de variáveis, como ocorre na análise fatorial.

Por meio da análise de coeficiente de aglomeração (MALHOTRA, 2006), a opção de 2 clusters se mostrou mais apropriada após as duas tentativas. O método utilizado foi de Ward e o intervalo de medida foi o Quadrado da Distância Euclidiana.

Dessa forma, foi realizada a Análise Discriminante para identificar as variáveis que discriminam os dois grupos obtidos na Análise de Cluster.

Consideradas as características das variáveis que discriminaram os dois Clusters, verifica-se que eles estão relacionados à identificação com o curso e também a certeza de que o mesmo e a universidade têm boa reputação/imagem e por isso é a melhor decisão profissional. Assim, há um grupo de acadêmicos que concordam em maior grau com essas afirmativas e outros que concordam em menor grau ou mesmo discordam em algum grau de tais afirmativas.

Tabela 4 - Análise discriminante

\begin{tabular}{l|l|r|r}
\hline Etapa & \multicolumn{1}{|c|}{ Entrada da variável } & Wilks' Lambda & Significância \\
\hline 1 & $\begin{array}{l}\text { Q7.7 Eu ainda não tenho certeza de minha identificação com o curso e com } \\
\text { a carreira de Administrador(a) }\end{array}$ & 0,538 & 0,000 \\
\hline 2 & Q6.16 Eu gosto bastante das disciplinas do curso de Administração & 0,408 & 0,000 \\
\hline 3 & $\begin{array}{l}\text { Q7.6 Eu acredito que os empregadores avaliam positivamente a profissão } \\
\text { de Administrador(a) }\end{array}$ & 0,372 & 0,000 \\
\hline 4 & $\begin{array}{l}\text { Q6.12 A imagem de mercado de minha instituição tem influência positiva } \\
\text { sobre o valor de meu diploma no mercado }\end{array}$ & 0,357 & 0,000 \\
\hline
\end{tabular}

* Escala foi invertida na análise dos dados.

Fonte: dados da pesquisa.

Por meio da Tabela 5, verifica-se que o Cluster 1, o qual foi denominado de vocacionados, apresenta como característica fundamental o elevado grau de concordância com as variáveis que discriminaram os dois grupos, demonstrando grande afinidade com a escolha do curso de administração e da universidade.

Por sua vez, o segundo cluster, apresentou menores níveis de concordância com a escolha do curso e da instituição, de acordo com as variáveis discriminantes, dessa forma, foi denominado de indecisos, por conter um grupo de discentes com menor grau de identificação com o curso, mas, mesmo assim, estão a cursá-lo.

Tal situação possivelmente remeta ao fato de o curso de Administração ser considerado por estes uma segunda opção, em virtude de não terem conseguido ingressar no curso desejado. Por outro lado, pode representar algum grau de insatisfação com a instituição, com o curso, com o grupo social e com as perspectivas da futura carreira. Todavia, este trabalho não se propõe a responder tais questões, sendo estas algumas oportunidades para estudos futuros. 
Tabela 5 - Grau de concordância por cluster com as variáveis que os discriminaram

\begin{tabular}{|c|c|c|c|c|c|c|c|c|}
\hline \multirow{3}{*}{ Nota* } & \multicolumn{8}{|c|}{ Variáveis } \\
\hline & \multicolumn{2}{|l|}{ Q7.7 } & \multicolumn{2}{|c|}{ Q6.16 } & \multicolumn{2}{|c|}{ Q7.6 } & \multicolumn{2}{|c|}{ Q6.12 } \\
\hline & Vocacionados & Indeciso & Vocacionado & Indeciso & Vocacionado & Indeciso & Vocacionado & Indeciso \\
\hline 1 & $0,00 \%$ & $18,20 \%$ & $0,00 \%$ & $3,00 \%$ & $0,00 \%$ & $4,50 \%$ & $0,00 \%$ & $1,50 \%$ \\
\hline 2 & $0,00 \%$ & $13,60 \%$ & $0,00 \%$ & $10,60 \%$ & $0,00 \%$ & $3,00 \%$ & $0,00 \%$ & $0,00 \%$ \\
\hline 3 & $0,00 \%$ & $13,60 \%$ & $0,00 \%$ & $19,70 \%$ & $0,00 \%$ & $21,20 \%$ & $0,00 \%$ & $1,50 \%$ \\
\hline 4 & $0,00 \%$ & $19,70 \%$ & $8,10 \%$ & $30,30 \%$ & $8,10 \%$ & $31,80 \%$ & $2,70 \%$ & $12,10 \%$ \\
\hline 5 & $0,00 \%$ & $12,10 \%$ & $35,10 \%$ & $27,30 \%$ & $45,90 \%$ & $25,80 \%$ & $13,50 \%$ & $40,90 \%$ \\
\hline 6 & $13,50 \%$ & $9,10 \%$ & $21,60 \%$ & $9,10 \%$ & $27,00 \%$ & $12,10 \%$ & $40,50 \%$ & $33,30 \%$ \\
\hline 7 & $86,50 \%$ & $13,60 \%$ & $35,10 \%$ & $0,00 \%$ & $18,90 \%$ & $1,50 \%$ & $43,20 \%$ & $10,60 \%$ \\
\hline Total & $100,00 \%$ & $100,00 \%$ & $100,00 \%$ & $100,00 \%$ & $100,00 \%$ & $100,00 \%$ & $100,00 \%$ & $100,00 \%$ \\
\hline
\end{tabular}

A seguir, são apresentadas as características de cada cluster, sendo que o cluster composto por 37 acadêmicos foi denominado de vocacionados e o cluster composto 66 acadêmicos foi chamado de indecisos. Quatro acadêmicos não foram classificados em nenhum dos clusters.

Tabela 6 - Cluster por instituição

\begin{tabular}{l|c|c|c}
\hline \multirow{2}{*}{ Instituição } & \multicolumn{2}{|c|}{ Cluster } & \multirow{2}{*}{ Total } \\
\cline { 2 - 3 } & Vocacionados & Indecisos & \\
\hline \multirow{2}{*}{ IFMinas } & 24 & 46 & 70 \\
& $64,9 \%$ & $69,7 \%$ & $68,0 \%$ \\
\hline \multirow{2}{*}{ IFSul } & 13 & 20 & 33 \\
& $35,1 \%$ & $30,3 \%$ & $32,0 \%$ \\
\hline \multirow{2}{*}{ Total } & 37 & 66 & 103 \\
\hline Fonte: & $100,0 \%$ & $100,0 \%$ & $100,0 \%$ \\
\hline
\end{tabular}

Fonte: Dados da pesquisa

Conforme demonstrado na Tabela 6, tanto dentre os grupos dos vocacionados quanto dos indecisos os estudantes da IFMinas, por terem o peso de $68 \%$ dos correspondentes totais, têm a maioria nos dois clusters. Porém, ao analisar de maneira separada, isto é, o quanto da porcentagem cada cluster corresponde do total de cada universidade, a IFSUL se destaca frente à IFMinas, por ter $39,39 \%$ pertencentes ao grupo dos vocacionados, frente a $34,28 \%$ da universidade mineira. Todavia, trata-se de uma diferença muito pequena.

De maneira análoga, por sua vez, ao analisar o cluster dos indecisos a IFMinas possui $65,71 \%$ em relação dos seus 70 respondentes, frente a $60,60 \%$ dos 33 respondentes da IFSul, demonstrando que os estudantes da primeira universidade estão mais indecisos que o da segunda universidade, sendo, entretanto, uma consideração restrita à amostra em questão.

Ao analisar a Tabela 7, percebe-se que no grupo dos vocacionados, frente aos indecisos, uma maior parcela, $48,60 \%$, exerce também algum tipo de trabalho remunerado, além de estudar. Enquanto no grupo 
no grupo de indecisos a maioria de $62,10 \%$ apenas estuda. Possivelmente, o fato de já trabalharem na área colabora para que os estudantes se sintam mais motivados em relação ao curso.

Tabela 7 - Tipo de dedicação ao curso por cluster

\begin{tabular}{l|ccc}
\hline Tipo de Dedicação ao Curso & Vocacionados & Indecisos & Total \\
\hline Dedica-se exclusivamente ao curso & 19 & 41 & 60 \\
& $51,40 \%$ & $62,10 \%$ & $58,30 \%$ \\
\hline Exerce também algum tipo de trabalho remunerado & 18 & 25 & 43 \\
& $48,60 \%$ & $37,90 \%$ & $41,70 \%$ \\
\hline Total & 37 & 66 & 103 \\
& $100,00 \%$ & $100,00 \%$ & $100,00 \%$ \\
\hline
\end{tabular}

Fonte: Dados da pesquisa

Ao cruzar o motivo para a realização do curso com os dois clusters encontrados, o resultado foi a Tabela 8. Ao analisar a Tabela 8 percebe-se que o grupo dos vocacionados se mostra mais bem distribuído entre as seis opções disponíveis, frente ao dos indecisos. De maneira específica, ao marcarem $13,90 \%$ contra 4,70\% na opção "Preparação para gerenciar empresa própria ou da família", juntamente com a porcentagem de $25,00 \%$ contra $15,60 \%$ na opção "Adquirir conhecimentos para abrir meu próprio negócio", fica evidente que o primeiro grupo se apresenta mais vocacionado que o segundo, por terem uma preferência maior em arriscar e abrir seu próprio negócio ou da família, do que o segundo grupo.

Indo ao encontro de tal visão, ao analisar o grupo dos indecisos a maioria, 64,10\% está se preparando para conseguir um emprego, seja ele público ou privado. Além disso, 6,30\% escolherem o curso por que estavam com falta de opção, contra nenhuma resposta do grupo dos vocacionados.

Tabela 8 - Motivo de realização do curso por cluster

\begin{tabular}{lccc}
\hline Motivo & Vocacionados & Indecisos & Total \\
\hline Preparação para conseguir um emprego (público ou privado) & 18 & 41 & 59 \\
\hline Para melhorar minha prática profissional & $50,00 \%$ & $64,10 \%$ & $59,00 \%$ \\
\hline Porque meu emprego exigia formação superior & 1 & 2 & 3 \\
& $2,80 \%$ & $3,10 \%$ & $3,00 \%$ \\
\hline Preparação para gerenciar empresa própria ou da família & 0 & 1 & 1 \\
& $0,00 \%$ & $1,60 \%$ & $1,00 \%$ \\
\hline Adquirir conhecimentos para abrir meu próprio negócio & 5 & 3 & 8 \\
\hline Falta de opção & $13,90 \%$ & $4,70 \%$ & $8,00 \%$ \\
\hline Outros & 9 & 10 & 19 \\
\hline Total & $25,00 \%$ & $15,60 \%$ & $19,00 \%$ \\
\hline
\end{tabular}

Fonte: Dados da pesquisa 
Ao cruzar a pretensão após a conclusão do curso com os dois clusters encontrados, o resultado foi a Tabela 9. Ao analisar-se a Tabela 9 percebe-se que no grupo dos indecisos há uma porcentagem significativa $(15,40 \%)$ que pretende fazer outro curso de graduação, reforçando a ideia de insatisfação dos mesmos em relação ao curso. Por outro lado, ao analisar o grupo dos vocacionados uma grande parcela $(47,20 \%)$ pretende fazer um curso de especialização, reforçando a ideia de que eles estão satisfeitos com a graduação escolhida, pois, considera-se que a especialização é um avanço nos estudos feitos na graduação.

Tabela 9 - Pretensão após a conclusão do curso por cluster

\begin{tabular}{lccc}
\hline Pretensão & Vocacionados & Indecisos & Total \\
\hline Parar de estudar por um período e somente trabalhar & 6 & 13 & 19 \\
\hline Fazer outro curso de graduação & $16,70 \%$ & $20,00 \%$ & $18,80 \%$ \\
\hline Fazer um curso de especialização & 1 & 10 & 11 \\
& $2,80 \%$ & $15,40 \%$ & $10,90 \%$ \\
\hline Fazer um curso de mestrado & 17 & 22 & 39 \\
\hline Outros & $47,20 \%$ & $33,80 \%$ & $38,60 \%$ \\
\hline Total & 8 & 14 & 22 \\
& $22,20 \%$ & $21,50 \%$ & $21,80 \%$ \\
\hline
\end{tabular}

Fonte: Dados da pesquisa

Segundo a Tabela 10, analisando o grupo dos vocacionados a maioria $(62,20 \%)$ é do sexo feminino. E pelo contrário, quando se analisa o grupo dos indecisos tal porcentagem é invertida, sendo que a maioria $(59,10 \%)$ é do sexo masculino. Tais constatações demonstram que as mulheres são mais vocacionadas ao curso de Administração frente aos homens na amostra obtida.

Tabela 10 - Sexo dos acadêmicos por cluster

\begin{tabular}{lccc}
\hline Sexo & Vocacionados & Indecisos & Total \\
\hline \multirow{2}{*}{ Masculino } & 14 & 39 & 53 \\
& $37,80 \%$ & $59,10 \%$ & $51,50 \%$ \\
\hline \multirow{2}{*}{ Feminino } & 23 & 27 & 50 \\
& $62,20 \%$ & $40,90 \%$ & $48,50 \%$ \\
\hline \multirow{2}{*}{ Total } & 37 & 66 & 103 \\
& $100,00 \%$ & $100,00 \%$ & $100,00 \%$
\end{tabular}

Fonte: Dados da pesquisa 


\section{Análise de regressão - mínimos quadrados ordinários}

A Regressão Múltipla é usada para analisar a relação entre uma única variável dependente, chamada de critério, e inúmeras variáveis independentes (preditoras), com o objetivo de usar as variáveis independentes, de valores conhecidos, para prever os valores da variável dependente selecionada. Para aplicar a regressão múltipla deve-se: (1) ter dados métricos ou devidamente transformados; (2) definir variáveis que serão independentes e a variável dependente (HAIR Jr. et al, 2005).

De acordo com Figueiredo Filho et al (2011), em regressões multivariadas (com mais de uma variável independente) se pode identificar a contribuição de cada variável independente sobre a capacidade preditiva do modelo como um todo. Para esses autores, tecnicamente, quando o modelo é ajustado utilizando a forma funcional de mínimos quadrados ordinários representa-se que uma reta que minimiza a soma dos quadrados dos resíduos será utilizada para resumir a relação linear entre $Y$ e $X_{i}$.

Para verificar e identificar um modelo que se ajustasse significativamente e representasse relações entre dois ou mais construtos obtidos neste trabalho, foram realizadas diversas análises por meio do software GRETL, valendo-se da técnica de Análise de Regressão Múltipla por Mínimos Quadrados Ordinários. Para cada fator foi considerado o valor médio de suas respectivas variáveis, por respondente.

Tabela 11 - Análise de regressão (MQO)

\begin{tabular}{lrrrr}
\hline Variável & Coeficiente & Erro Padrão & razão-t & p-valor \\
\hline Valor Epistêmico & 0,209 & 0,097 & 2,161 & $0,033^{* *}$ \\
Valor Social & 0,156 & 0,077 & 2,020 & $0,046^{* *}$ \\
Identificação com a Profissão & 0,594 & 0,075 & 7,902 & $0,000^{* * *}$ \\
\hline
\end{tabular}

\section{Observações:}

Média da variável dependente $=$

Soma dos quadrados dos resíduos $=$

66,765

$\mathrm{R}^{2}=$

0,975

$F(3,104)=$

$1.351,219$

Log da verossimilhança $=$

$-126,594$

Critério de Schwarz =

267,205

Teste RESET para especificação -

Hipótese nula: a especificação é adequada

Estatística de teste: $F(2,102)=1,296$

com $p$-valor $=P(F(2,102)>1,296)=0,278$

Teste da normalidade dos resíduos -

Hipótese nula: o erro tem distribuição Normal

Estatística de teste: Qui-quadrado(2) = 3,009

com $p$-valor $=0,222$

Fonte: Dados da pesquisa.
Desvio Padrão da variável dependente $=\quad 1,131$

Erro Padrão da regressão $=\quad 0,801$

$\mathrm{R}^{2}$ ajustado $=\quad 0,975$

p-valor $(F)=\quad 0,000$

Critério de Akaike $=\quad 259,187$

Critério Hannan-Quinn $=\quad 262,438$

Teste de White para a heteroscedasticidade -

Hipótese nula: sem heteroscedasticidade

Estatística de teste: $L M=6,811$

com p-valor $=\mathrm{P}($ Qui-quadrado $(9)>6,811)=0,657$ 
O modelo que apresentou o melhor ajuste (Tabela 11) leva à afirmação de que o Valor Funcional percebido pelos estudantes de graduação em relação ao curso de bacharelado em Administração é uma função (Equação 1) do Valor Epistêmico e do Valor Social percebido em relação ao curso, bem como, da sua Identificação com a Profissão de Administrador.

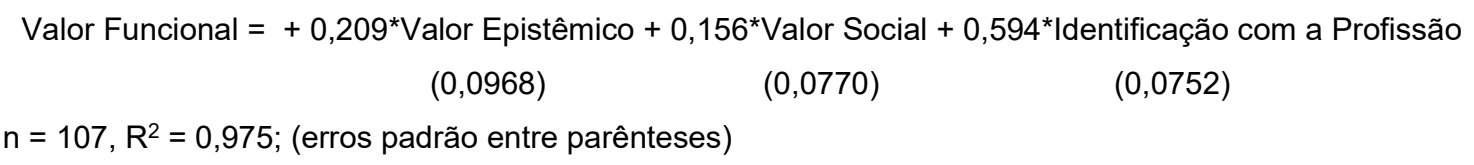

Por meio dos resultados da Tabela 11, verifica-se também que o teste RESET de especificação do modelo rejeitou a hipótese alternativa, corroborando a hipótese nula de especificação adequada do modelo. Da mesma forma, o modelo não apresentou problema de heteroscedasticidade e os resíduos apresentaram distribuição normal. Dessa forma, ratifica-se a adequação do modelo proposto.

Diante de tais resultados, pode-se concluir, neste trabalho, que o Valor Funcional percebido pelos estudantes entrevistados (desejo de satisfação relacionado à certeza da escolha correta da profissão) com o curso de Administração é explicado em parte pela avaliação do Valor Epistêmico (curso, instituição etc.), do Valor Social (envolvendo elementos como a avaliação positiva da instituição de ensino pela sociedade, ambiente universitário, relações sociais etc.) e pela Identificação com a Profissão.

Nesse sentido, corrobora-se o que afirmam Regio et al (2014) de que processo de escolha de uma carreira profissional relaciona-se com uma alocação ótima de risco e retorno entre cada opção, sendo que fatores mais subjetivos também influenciam as escolhas de carreira entre pessoas, tais como o status que a mesma proporciona aos profissionais.

\section{CONSIDERAÇÕES FINAIS}

Este trabalho foi realizado com o intuito de verificar como os estudantes de Administração de duas universidades federais avaliam seus cursos, baseado nas perspectivas do serviço de formação recebido, da profissão e da identificação pessoal a partir da abordagem proposta por Costa e Oliveira (2008; 2011). Conforme apresentado os objetivos foram: (1) analisar a percepção de valor dos estudantes no serviço de formação recebido, o nível de identificação do aluno com a profissão e a percepção de prestígio na profissão;

(2) desenvolver uma tipologia dos estudantes a partir dos tópicos temáticos da pesquisa (valor, identificação e prestígio); (3) identificar relações entre os construtos.

Acredita-se que os objetivos apresentados foram plenamente alcançados, conforme foi detalhado na apresentação e discussão dos resultados, ou seja: (1) foi analisada a percepção de valor dos estudantes no serviço de formação recebido, o nível de identificação do aluno com a profissão e a percepção de prestígio na profissão; (2) foi desenvolvida uma tipologia dos estudantes a partir dos tópicos temáticos da pesquisa (valor, identificação, e prestígio), gerando a classificação dos estudantes vocacionados e dos indecisos com a profissão; e, (3) foram identificando relações entre alguns construtos, sendo que por meio da regressão múltipla verificou-se que o valor funcional é uma função do valor epistêmico, do valor social e da identificação com a profissão de administrador. 
Diferentemente das cinco escalas para valor encontradas pelos autores Costa e Oliveira (2008) neste estudo, pela análise fatorial foram encontradas apenas quatro, sendo elas valor epistêmico, valor de reputação/imagem, valor social, valor funcional (desejo de satisfação). Não houve significância na categoria valor emocional. Cabe ressaltar que as variáveis associadas a valor funcional (preço/qualidade), não foram incluídas neste estudo.

Neste trabalho, a partir da análise dos dados, foi possível a formação de dois clusters, o primeiro grupo foi denominado de vocacionado, o qual, pode dizer que estão mais satisfeitos e identificado com o curso de Administração e outro chamado de indecisos, o qual possui um grau menor de identificação e satisfação com o mesmo.

Em relação aos clusters, a IFSul se destaca à IFMinas, por ter uma porcentagem maior de seus estudantes pertencentes ao grupo dos vocacionados. Além disso, o grupo de vocacionados possuem ambições maiores, tal como abrir sua própria empresa, do que apenas se preparar para conseguir um emprego (público ou privado), ao se tratar da motivação para a escolha do curso de Administração. Ademais, uma parcela significativa do grupo de indecisos faria outros cursos ao formar, por sua vez uma grande parcela dos vocacionados fariam uma especialização na área, reafirmando sua posição frente à escolha do curso. Por fim, as mulheres se mostraram mais vocacionadas e os homens mais indecisos.

Em termos de limitações, ao levar em consideração que este é um trabalho quantitativo, cabe ressaltar que a amostra levantada foi por conveniência, não permitindo assim extrapolar seus resultados para a população de estudantes das duas universidades.

Uma relevante consideração deste trabalho está no fato da grande parcela identificada de estudantes de administração indecisos com a profissão, o que leva a acreditar que parte dos alunos realizam o curso, o fazem por ser uma segunda opção e não aquela de fato desejada. Todavia, este trabalho não responde a esta questão e tal afirmativa é colocada como sugestão para um levantamento qualitativo futuro com estudantes de administração das universidades aqui citadas para compreender tal fenômeno.

Diferentemente dos resultados encontrados por Costa (2008), os quais indicaram que as avaliações dos alunos são mais positivas nos dois primeiros anos de curso, período em que os alunos demostram um elevado entusiasmo, neste estudo, não houve uma distinção relacionada ao período cursado. A principal contribuição aqui se refere aos dois perfis distintos dos estudantes, identificados através dos clusters. Ao considera-se o cluster dos "vocacionados", por outro lado, há uma corroboração com os estudos de Oliveira (2011), o qual mostrou também uma consolidação de uma identidade profissional sólida.

Como sugestões para trabalhos futuros, são propostos estudos similares em outras universidades (com amostragens probabilísticas), sejam federais, estaduais ou particulares, pois, conforme mostrado aqui, os resultados a respeito dos valores, prestígio e identificação com o curso variam dependendo do contexto da cidade em que a universidade está situada. Além disso, ainda se carece de estudos dessa natureza nas áreas administrativas, conforme foi mostrado por Costa e Oliveira (2008), por isso, sugere-se mais estudos com o escopo voltado para os cursos de Administração. 


\section{REFERÊNCIAS}

BASTOS, A. V. B.; CORREA, N. C. N.; LIRA, S. B. Padrões de comprometimento com a profissão e a organização: o impacto de fatores pessoais e da natureza do trabalho. In: ENCONTRO ANUAL DA ASSOCIAÇÃO NACIONAL DE PÓS-GRADUAÇÃO EM ADMINISTRAÇÃO - ENANPAD, 22., Foz do Iguaçu, 1998. Anais eletrônicos... Foz do Iguaçu: ANPAD, 1998.

BREI, V.; ROSSI, C. confiança, valor percebido e lealdade em trocas relacionais de serviço: um estudo com usuários de internet banking no Brasil. In: ENCONTRO NACIONAL DOS PROGRAMAS DE PÓS-GRADUAÇÃO EM ADMINISTRAÇÃO, 26., 2002, Salvador. Anais... Rio de Janeiro: ANPAD, 2002.

CAMPOS, R. Identidade profissional. In: FIDALGO, F.; MACHADO, L. Dicionário da educação profissional. Belo Horizonte: Núcleo de Estudos sobre Trabalho, 2000.

CARVALHO, J. R. M.; SILVA, M.; HOLANDA, F. M. A. Perspectivas dos formandos do curso de Ciências Contábeis em relação ao mercado de trabalho de uma IES pública no estado do Rio Grande do Norte. Encontro da Associação Nacional de Pós Graduação e Pesquisa em Administração. 30. Anais eletrônicos... Salvador: ANPAD, 2006.

CFA. CONSELHO FEDERAL DE ADMINISTRAÇÃO. Censo dos Cursos. 2015. Disponível em: < http://www.cfa.org.br/servicos/formacao-profissional/censo-dos-cursos-de-bacharelado-em-administracao-e-dos-cursossuperiores-de-tecnologia-nas-diversas-areas-da-administracao> Acesso em 11 de maio de 2017.

CLAYSON, D. E.; HALEY, D. A. Marketing models in education: students as customers, products, or partners. Marketing Education Review. v. 15, n. 1, p. 1-11, Spring 2005.

COSTA, F. J. da. Formação em administração na perspectiva do aluno: valor percebido no curso, percepção do prestígio e identificação com a profissão. Revista Ciências Administrativas, v. 14, n. 1, 2008.

COSTA, F. J. da; OLIVEIRA, L. G. L. Valor Percebido, Prestígio e Identificação com a Profissão: uma Análise Junto a Estudantes de Contabilidade. Revista de Contabilidade do Mestrado em Ciências Contábeis da UERJ, v. 16, n. 1, p. 3546, 2011.

COSTA, F. J. da; OLIVEIRA, L. G. L.. Valor percebido no curso, percepção do prestígio e identificação com a profissão: uma análise junto a estudantes de administração e contabilidade. Revista de Administração da UFSM, v. 1, n. 3, 2008.

FARRELL, C. The development of a marketingself-efficacy scale: an assessment of reliability and construct validity. Marketing Education Review, v. 16, n. 3, p. 25-34, 2006.

FIGUEIREDO FILHO, D. et al. O Que Fazer e o Que Não Fazer Com a Regressão: pressupostos e aplicações do modelo linear de Mínimos Quadrados Ordinários (MQO). Revista Política Hoje, v. 20, n. 1, 2011.

FREIDSON, E. Para uma análise comparada das profissões: a institucionalização do discurso e do conhecimento formais. Revista Brasileira de Ciências Sociais. Vol. 11, N. 31, p. 141-154, jun. 1996.

GALINDO, W. C. M. A construção da identidade profissional docente. Psicologia: ciência e profissão, Vol.24, № 2, p. 1423, Junho, 2004.

GARDNER, B. What do customers value? Quality Progress, Milwankee, v. 34, n. 11, p. 41-48, Nov. 2001.

GASSENHEIMER, J. B.; HOUSTON, F. S.; DAVIS, J. C. The role of economic value, social value, and perceptions of fairness in interorganizational relationship retention decision. Journal of the Academy of Marketing Science, Thousands Oaks, v. 26, n. 4, p. 322-337, 1998.

GONÇALVES, W. A. et al. A PERSPECTIVA DO JOVEM, FUTURO GESTOR, FRENTE AOS DESAFIOS PROPOSTOS PELOS ESTUDOS ORGANIZACIONAIS: um diagnóstico preliminar quanto a sua futura atuação. Estudos do CEPE, n. 41, p. 153-169, 2015.

GUTMAN, J. A Means-end chain model based on consumer categorization processes. Journal of Marketing, Chicago, v. 46, n. 2, p. 60-72, 1982.

HAIR Jr., J.F.; ANDERSON, R.E.; TATHAM, R.L.; BLACK, W.C. Análise multivariada de dados. 5 ed. Porto Alegre: Bookman, 2005.

HOUSTON, F. S.; GASSENHEIMER, J. B. Marketing and exchange. Journal of Marketing, Chicago, v. 51, n. 4, p. 03-18, Oct. 1987.

IIZUKA, E. S.; MORAES, G. H. S. M. Potencial e Perfil Empreendedor do Estudante de Administração e o Ambiente Universitário: Investigação em três IES de São Paulo, Anais. 2014.

LACERDA, J. R.; REIS, S. M.; SANTOS, N. A. Os fatos extrínsecos e intrínsecos que motivam os alunos na escolha e na permanência no curso de ciências contábeis: um estudo da percepção dos discentes numa universidade pública. Encontro da Associação Nacional de Pós-Graduação e Pesquisa em Administração. 31. Anais eletrônicos... Rio de Janeiro: ANPAD, 2007.

LEBLANC, G.; NGUYEN, N. Listening to the customer's voice: examining perceived service value among business college students. The International Journal of Educational Management, v. 13, n. 4, p. 187-198, 1999. 
LINO, M. M. Satisfação profissional entre enfermeiras de UTI: adaptação transcultural do Index of Work Satisfaction (IWS). 238f.. Tese (Doutorado em Enfermagem). Escola de Enfermagem da Universidade de São Paulo. São Paulo, 2004.

MALHOTRA, N. K. Pesquisa de marketing: uma orientação aplicada. Porto Alegre: Bookman, 2001. 719 p.

OLIVEIRA, P. W. S. de. Construção de identidades profissionais: da formação profissional à vivência da inserção no mercado de trabalho. Revista Labor, 2011, 1.6: 115-133.

REGIO, M. de L. S. et al. Gestão de competências profissionais na formação de administradores. Avaliação: Revista da Avaliação da Educação Superior, v. 19, n. 1, p. 131-155, 2014.

REICHHELD, F. A estratégia da lealdade: a força invisível que mantém clientes e funcionários e sustenta crescimento, lucros e valor. Rio de Janeiro: Campus, 1996. 363 p.

SANTOS, M. F. S. Identidade e aposentadoria. São Paulo: EPU, 1990.

SILVA, E. L.; CUNHA, M. V. A formação profissional no século XXI: desafios e dilemas. Ciência da Informação. v. 31, n. 3, p. 77-82, Set./Dez. 2002

SIRDESHMUKH, D.; SINGH, J.; SABOL, B. Consumer trust, value, and loyalty in relational exchanges. Journal of Marketing, Chicago, v. 66, n. 1, p. 15-37, Jan. 2002.

SOUSA, D.; OLIVEIRA, L. H.; REZENDE, D.C. As relações entre confiança, valor e lealdade no contexto da educação à distância: um estudo de caso em uma universidade federal. Anais do XXX Encontro da ANPAD, v. 23, 2006.

ZEITHAML, V. A. Consumer perceptions of price, quality and value: a means-end model and synthesis of evidence. Journal of Marketing, Chicago, v. 52, n. 3, p. 02-22, July 1988. 